\title{
A FATIGUE FRACTURE STUDY ON TDCB ALUMINUM FOAM SPECIMEN OF TYPE MODE III BONDED WITH ADHESIVE
}

\begin{abstract}
This paper studies the characteristics of junction structure of closed-cell type aluminum foam, which is generally used as a shock absorber. TDCB specimens were designed for mode III type with thickness as a variable and performed a fatigue experiment on them by thickness. As the result, the load value of all specimens peaks under 0 to 25 cycles and decreases as the cycles increase. As the specimen thickens by $10 \mathrm{~mm}$, the maximum load value is 1.2 times. When the thickness increases by $20 \mathrm{~mm}$, the maximum value increases by 1.5 times. This study result can be utilized by investigating the mechanical characteristics of TDCB specimens for mode III type under fatigue loading conditions systematically and efficiently.
\end{abstract}

Keywords: Aluminum foam, Fatigue fracture, Fatigue analysis, Load, Mode III type, Specimen thickness

\section{Introduction}

Based on its excellent physical and mechanical properties, aluminum foam is an ultra-light metal available for various areas, including a car bumper, shock absorption material in an aircraft, a ship material, etc. However, aluminum foam can be damaged easily when used without sufficient research. If it is used for mechanical structures, it can also cause damage and destruction or even casualties [1-4]. Therefore, this paper investigates the characteristic of junction structure for closed-cell type with aluminum foam, which is generally used as a shock absorber. By the single-lap adhesive method, TDCB specimens for mode III type with thickness as a variable were designed. The specimens have the different thickness made with the aluminum foam of closed-cell type manufactured by Foam tech. at Korea. The fatigue experiments made with a tensile tester were carried out [5-10]. The result of fatigue experiment in this study can be applied in reality in order to evaluate the fracture property of TDCB-form joint structures made by porous material aluminum foam and study the mechanical properties systematically [11-17].

\section{Study model and method}

In this study, TDCB specimens were designed for mode III type by the single-lap adhesive method on the basis of DCB specimen in the British Standards 7991:2001. As shown by Fig. 1, variable t of the TDCB model corresponds to the thickness, and the width, lower base and length of the model are $80 \mathrm{~mm}, 130 \mathrm{~mm}$ and $190 \mathrm{~mm}$, respectively. The section of specimen without slope has the front side of $50 \mathrm{~mm}$. Variable (t) has values of $35 \mathrm{~mm}$, $45 \mathrm{~mm}$ and $55 \mathrm{~mm}$ as three models respectively.

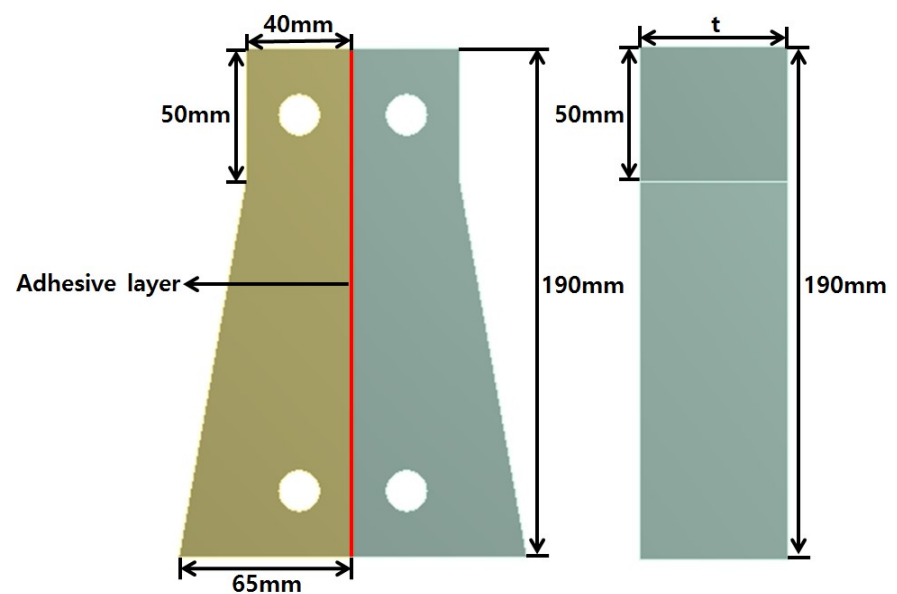

Fig. 1. Configuration of model

Fig. 2 shows the fatigue experimental method with TDCB specimens for mode III type to verify the result from simulation analysis. Since it is impossible to connect the specimens directly to the top and bottom load cells in the tensile tester with the experiment method, the specimens and tensile testers are connected by a jig, which we have additionally produced for the experiment. Top load cell is fixed, and the fatigue experiment

* DEPARTMENT OF MECHANICAL ENGINEERING, GRADUATE SCHOOL, KONGJU NATIONAL UNIVERSITY, CHEONAN-SI, REPUBLIC OF KOREA

** DIVISION OF MECHANICAL \& AUTOMOTIVE ENGINEERING, COLLEGE OF ENGINEERING, KONGJU NATIONAL UNIVERSITY, 1223-24 CHEONAN DAERO, SEOBUK-GU, CHEONAN-SI, CHUNGNAM 31080, REPUBLIC OF KOREA

\# Corresponding author: jucho@kongju.ac.kr 
are performed by applying the fatigue displacement of $\pm 6 \mathrm{~mm}$ in the -Z-axis direction and the fatigue cycle of $3 \mathrm{~Hz}$ with the bottom load cell. The tensile tester in this study is manufactured by MTS CO., LTD. This study uses Al-SAF40 for the aluminum foam, and its material property is shown in Table 1. Furthermore, the adhesive applied to the aluminum foam specimens has the aerosol type with the adhesive strength of $0.4 \mathrm{MPa}$.

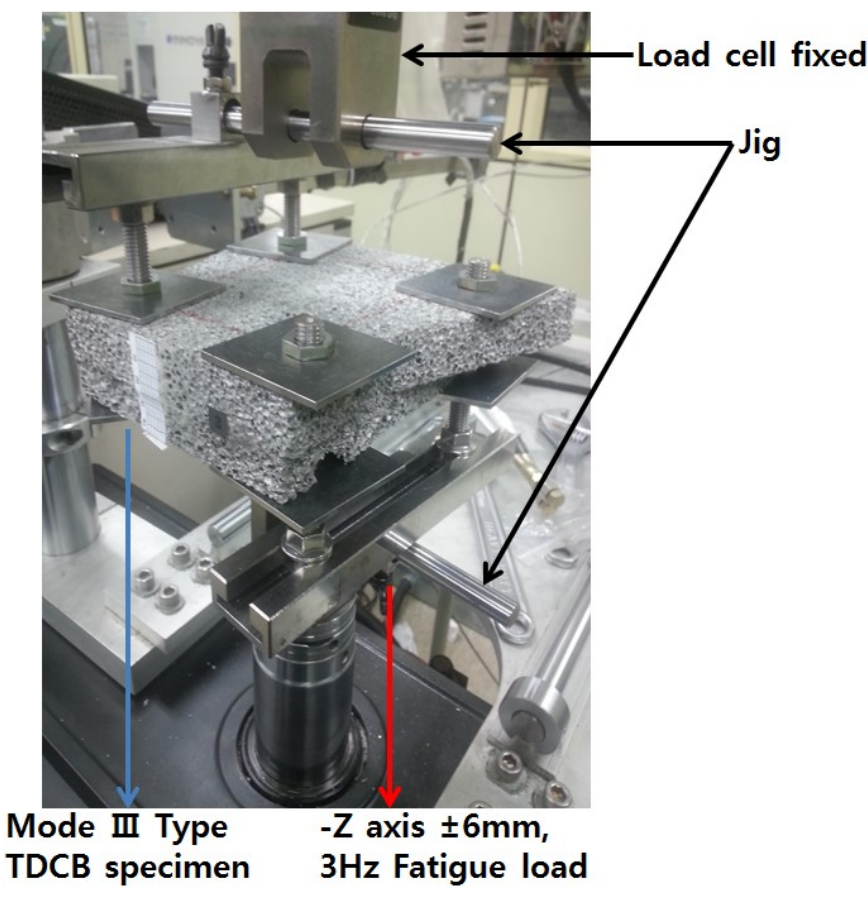

Fig. 2. Experimental conditions of fatigue experiment

TABLE 1

Mechanical properties of aluminum foam

\begin{tabular}{|c|c|}
\hline Property & Value \\
\hline Young's modulus (GPa) & 2.374 \\
\hline Poisson's ratio & 0.29 \\
\hline Density $\left(\mathrm{kg} / \mathrm{m}^{3}\right.$ ) & 400 \\
\hline Yield strength (MPa) & 1.8 \\
\hline Shear strength (MPa) & 0.29 \\
\hline
\end{tabular}

The simulation analysis of fatigue is carried out by using ANSYS program of finite element method. Fig. 3 shows the conditions for simulation analysis applied to three TDCB specimens, designed in this study. To generate a crack in the shear direction, the holes in one side of TDCB specimens have a fixed support and those on the other side are pulled in the -Zaxis direction repeatedly with the fatigue loading conditions of $\pm 6 \mathrm{~mm}$ of fatigue displacement and $3 \mathrm{~Hz}$ of fatigue cycle.

\section{Study result}

When performing the fatigue experiment by applying the fatigue displacement of $\pm 6 \mathrm{~mm}$ in the Z-axis direction and the fatigue cycle of $3 \mathrm{~Hz}$ with TDCB specimens, the load values of

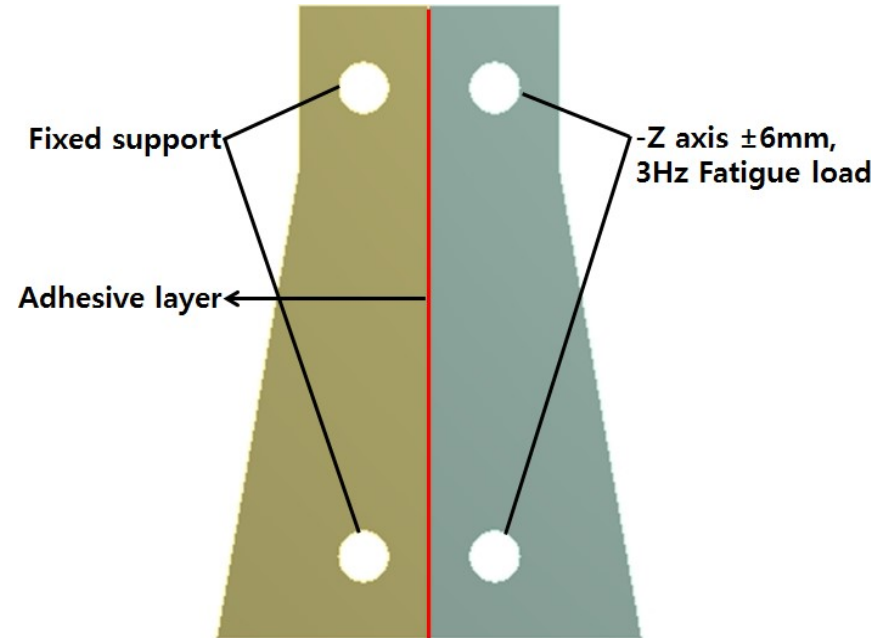

Fig. 3. Boundary conditions for fatigue analysis

the 35 mm TDCB specimen model by cycle are shown in Fig. 4. When the cycle increases under 0 to 25 , the load value is at the maximum level of $\pm 0.5 \mathrm{kN}$ and then decreases gradually under 25 cycles to 320 cycles from the point of time the maximum load happens. Under 320 to 375 cycles, the load value is maintained at about $0.01 \mathrm{kN}$.

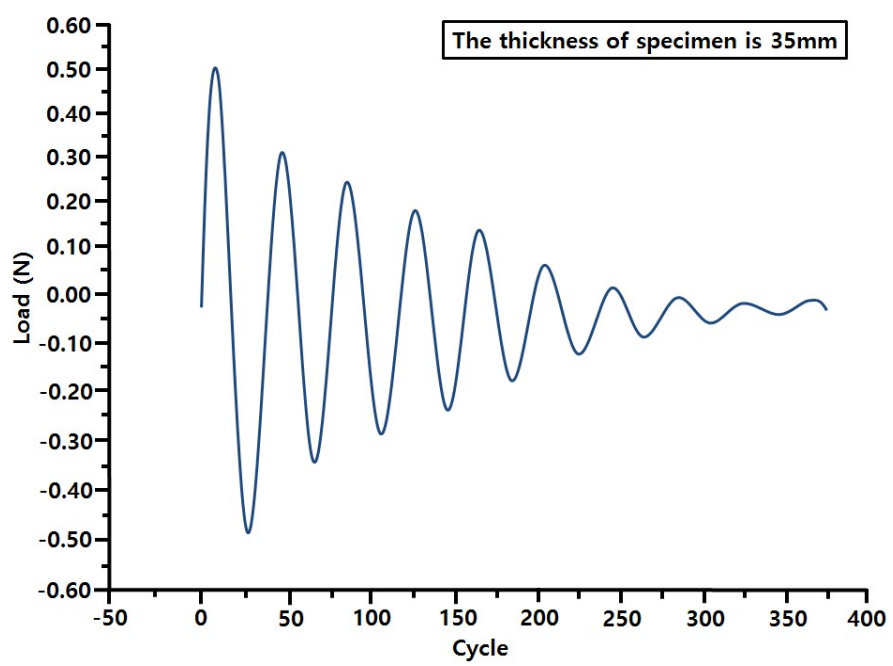

Fig. 4. Graph of load due to cycle at fatigue experiment (Thickness of specimen is $35 \mathrm{~mm}$ )

When performing the fatigue experiment by applying the fatigue displacement of $\pm 6 \mathrm{~mm}$ in the Z-axis direction and the fatigue cycle of $3 \mathrm{~Hz}$ with TDCB specimens, the load values of the $45 \mathrm{~mm}$ TDCB specimen model by cycle are shown in Fig. 5. When the cycle increases under 0 to 25 like the case of TDCB specimen with the thickness (t) of $35 \mathrm{~mm}$, the load value is at the maximum level of $\pm 0.6 \mathrm{kN}$, and then decreases gradually under 25 cycles to 320 cycles. Under 320 to 375 cycles, the load value is maintained at about $0.03 \mathrm{kN}$. By comparing with TDCB specimen with the thickness $(\mathrm{t})$ of $35 \mathrm{~mm}$, it is shown that the maximum load happening at specimen is bigger and this specimen endures bigger fatigue load. 


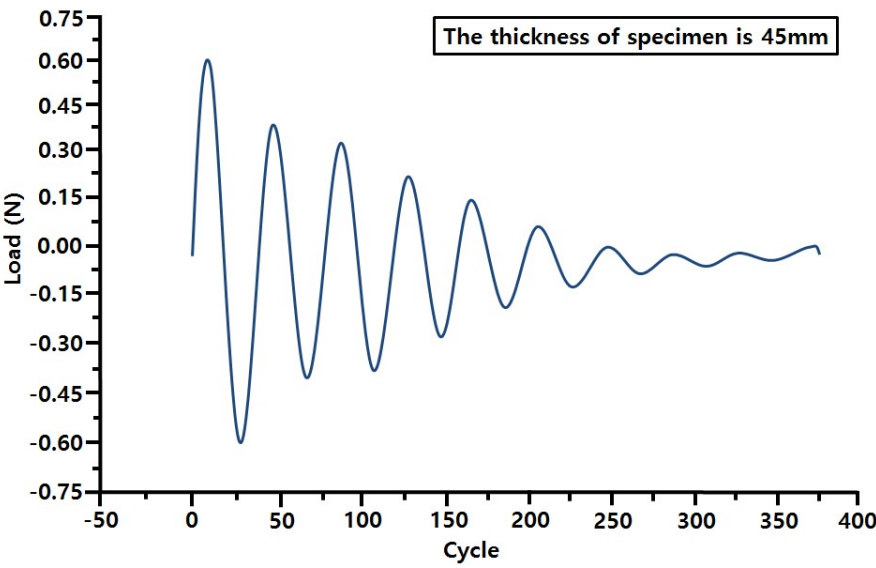

Fig. 5. Graph of load due to cycle at fatigue experiment (Thickness of specimen is $45 \mathrm{~mm}$ )

Fig. 6 shows the correlation between load values and cycles from the fatigue experiment with the $55 \mathrm{~mm}$ TDCB specimen model. Similar to the result above, the load value peaks between 0 to 25 cycles with the value of $\pm 0.75 \mathrm{kN}$ and gradually decreases from 25 to 320 cycles. Under 320 to 375 cycles, the load value is maintained at about $0.04 \mathrm{kN}$.

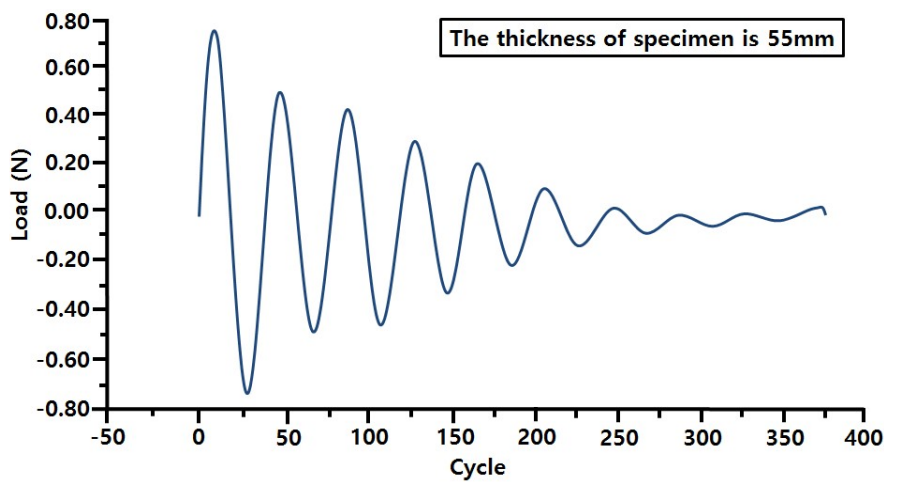

Fig. 6. Graph of load due to cycle at fatigue experiment (Thickness of specimen is $55 \mathrm{~mm}$ )

By comparing with TDCB specimens with the thicknesses (t) of $35 \mathrm{~mm}$ and $45 \mathrm{~mm}$, It is shown that the maximum load happening at the specimen thickness ( $\mathrm{t}$ ) of $55 \mathrm{~mm}$ becomes bigger and this specimen has the most durability.

The fatigue analysis for TDCB specimen model for type III is performed to compare and verify the result with the actual fatigue experiment. The analysis values are similar to those from the actual experiment by comparing the analysis and experimental results on specimen with the thickness of 55 mm. Fig. 7 compares the load values from the actual experiment and simulation analysis by cycle. Load value increases as the cycle increases, peaks at $0.72 \mathrm{kN}$ under 0 to 25 cycles, decreases afterwards, and the analysis value approaches the amplitude load of the actual experiment from 340 cycles. Because the simulation analysis is carried out except the external environmental factor at the practical experiment, the cycles are maintained a little longer on the whole at analysis than experiment. But it is shown that the maximum load and the whole load at analysis approach the practical experimental loads. The fatigue analysis data in this study can be applied in practice by allowing further studies to analyze the mechanical characteristics of TDCB specimens with type III under fatigue loading systematically and efficiently.

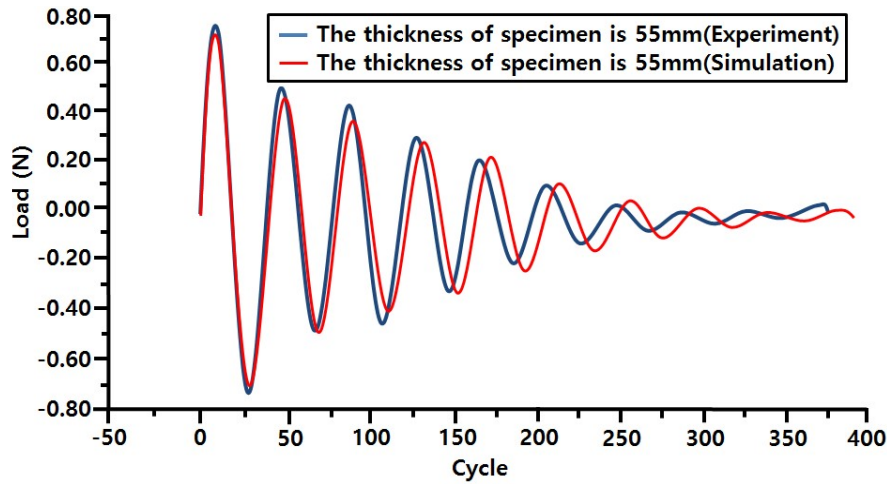

Fig. 7. Comparison between experimental and analysis data (Thickness of specimen is $55 \mathrm{~mm}$ )

\section{Conclusion}

This study investigates the fatigue experiment with TDCB specimens with each thickness for mode III type made of aluminum foam and are concluded as follows.

In the fatigue experiment, the load values of all specimens (with the thicknesses of $35 \mathrm{~mm}, 45 \mathrm{~mm}$ and $55 \mathrm{~mm}$ ) peak under 0 to 25 cycles and decreases as the cycle increases. Maximum load values of $35 \mathrm{~mm}, 45 \mathrm{~mm}$ and $55 \mathrm{~mm}$ of TDCB specimens are $\pm 0.5 \mathrm{kN}, \pm 0.6 \mathrm{kN}$ and $\pm 0.75 \mathrm{kN}$, respectively, increasing as the specimen thickens. Therefore, it is shown that the sustainable maximum load becomes bigger as the specimen thickness becomes thicker. On the basis of this result, the specimen with the thickness of $55 \mathrm{~mm}$ has the most fatigue durability than the specimens with the thicknesses of $35 \mathrm{~mm}$ and $45 \mathrm{~mm}$.

When comparing with the specimen thickness of $35 \mathrm{~mm}$, the maximum load value is 1.2 times as the specimen thickens by $10 \mathrm{~mm}$; and it increases by 1.5 times as the thickness increases by $20 \mathrm{~mm}$. The fatigue experiment data can be applied in reality by allowing further studies to investigate the mechanical characteristics of TDCB specimens for mode III-type under fatigue loading conditions systematically and efficiently.

\section{Acknowledgments}

This research was supported by Basic Science Research Program through the National Research Foundation of Korea (NRF) funded by the Ministry of Education, Science and Technology (2015R1D1A1A01057607). 


\section{REFERENCES}

[1] R. Davidson, R.J. Lee, MTS Adhesives Project 2 (1995).

[2] A. Pirondi, G. Nicoletto, Engineering Fracture Mechanics 71, 859 (2004).

[3] N.Y. Chung and S.I. Park, International Journal of Automotive Technology 5, 303 (2004).

[4] International Standards Organization, ISO 11343, Geneva 1993.

[5] British Standard, BS 7991 (2001).

[6] Annual Book of ASTM Standards, ASTM D3433 (1990).

[7] H.K. Choi, M.S. thesis, Kongju University, Cheonan, Cheonan Daero 1223-24, February.

[8] M.S. Han, H.K. Choi, J.U. Cho, C.D. Cho, International Journal of Precision Engineering and Manufacturing 14, 1395 (2013).

[9] R. Ahmad, J.H. Ha, Y.D. Hahn, I.H. Song, Journal of the Korean Powder Metallurgy Institute 19, 278 (2012).
[10] S.H. Lee, D.M. Hong, Journal of the Korean Powder Metallurgy Institute 21, 50 (2014)

[11] J.H. Choi, S.S. Yang, Y.D. Kim, J.Y. Yun, Journal of the Korean Powder Metallurgy Institute 20, 439 (2013).

[12] K.R. Pradeep, B.N. Rao, S.M. Srinivasan, K. Balasubramaniam, Eng. Fract. Mech. 93, 108 (2012).

[13] S.S. Kim, M.S. Han, J.U. Cho, C.D. Cho, International Journal of Precision Engineering and Manufacturing 14, 1791 (2013).

[14] H. Masaki, A. Tadashi, T. Mototsugu, A. Taiji, O. Shojiro, E. Yoshihiro, International Journal of Fatigue 28, 1154 (2006).

[15] F. Aymerich, R. Onnis, P. Priolo, Composites Science and Technology 66, 166 (2006).

[16] J.A. Harris, R.A. Adams, International Journal of Adhesion and Adhesives 4, 65 (1984).

[17] J.H. Lee, J.U. Cho, Journal of Korean Society Mechanical Technology 17, 916 (2015). 